\title{
The Application of Big Data Technology in Basic Computer Teaching of
}

\section{Ethnic Preparatory}

\author{
JieYuhan \\ The Two Branch School of Ethnic Education,Nanchang Institute of Science \&Technology,Nanchang \\ 330108,China
}

Keywords: basic computer; big data technology; flipped classroom;

\begin{abstract}
The computer foundation is a major course of ethnic preparatory education. In this paper, the research situation of traditional preparatory basic computer teaching has been analyzed, in view of the crisis of the teaching, the application background, characteristics and essence of big data technology has been expounded. It is important to apply big data technology to preparatory basic computer teaching, then we analyze a series of opportunities that bring to basic computer teaching, and it has been put forward that teaching methods of "flipped classroom" and teaching concept of students autonomous learning based, supplemented by teachers teaching, which can improve the matriculation students the ability to work in Colleges and universities in the future.
\end{abstract}

\section{Introduction}

National preparatory class is an important measure for the minority nationality regions of cultivate specialized talents in our country, but also a special running school mode that taken in our country to. Preparatory education has played a significant role in improving the cultural basic knowledge of minority students, and making more minority students enter the high and secondary professional schools, it is an important part of national education. In recent years, the number of matriculation enrollment continues is increasing, the research foundation education is of great value for the training of ethnic minorities. The basic computer course is the key point of the minority preparatory course, which has great significance to train the students' ability to operate and apply the computer, and to improve the quality of students. The teaching platform combining interactive and evaluation has been studied based on the big data technology in the paper. Internet resources and multimedia resources has been applied in teaching, which has multimode of teaching. The platform can realize knowledge exchange, suitable for teaching of teacher-student interaction, expert training, global student exchange learning, which can increase the interactivity of basic computer teaching.

\section{Big data technology}

Big data technology is developed with the network technology and cloud computing, it constitutes the huge volume data set, with the mobile communication technology that has fast data transmission and sensor network and the Internet of things technology that has strong perception as the representative. The data set covers a wide range of information, its content can not be handled effectively with common software tools in a certain period of time. With the advent of big data, it has provided a new analytical solution for some complex issues, in other words, the problem that be can not be solved by traditional software tools can be solved by big data technology. Big data is a technology that has basic theory and scientific research background, which includes distributed computing, memory computing, machine learning, computer vision, speech recognition, natural language processing in the field of computer advanced technology and these techniques derived from the new product. In fact, the big data technology is not only the method of sampling survey, 
but also the data processing method for all the data set. Big data technology has $4 \mathrm{~V}$ features, the characteristics of the framework is shown in Figure 1.

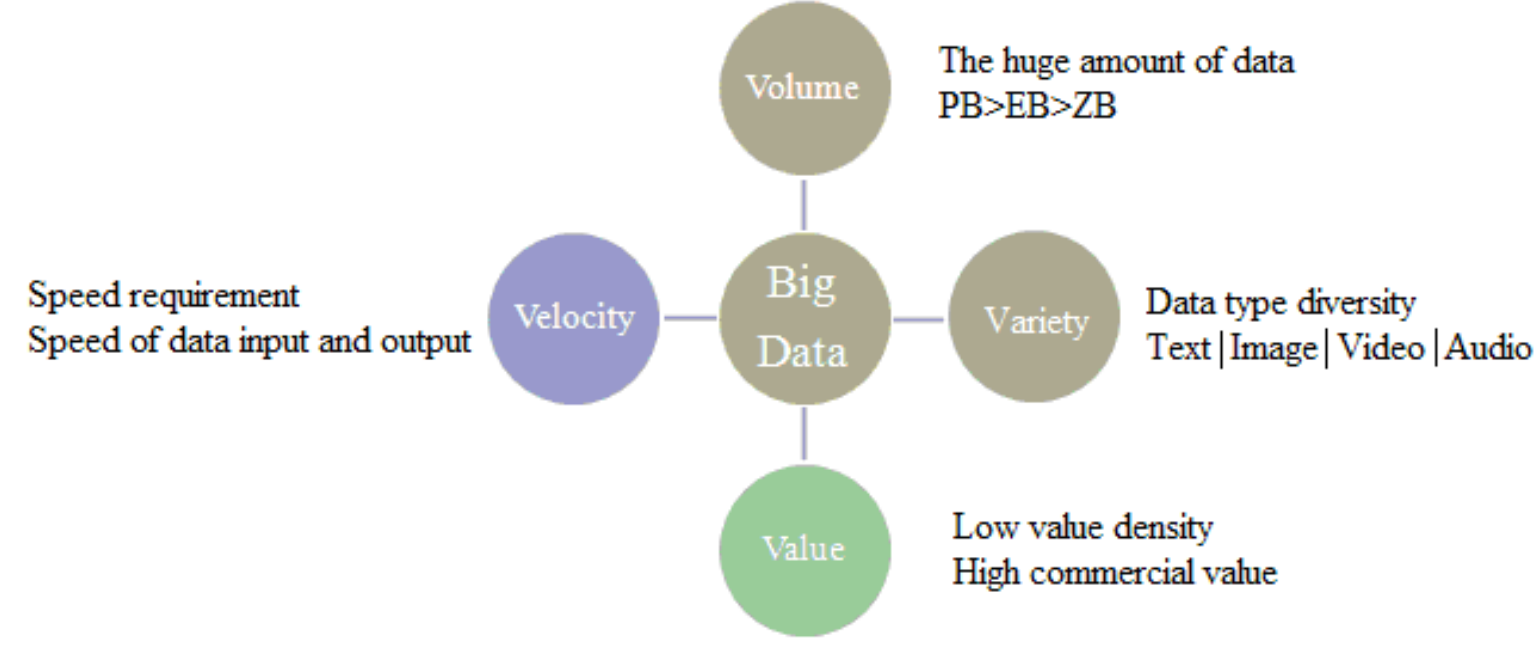

Fig. 1 Big data 4V feature framework

As shown in Figure 1, 4V features of big data includes Volume (big in data volume), Variety (data type variety), Velocity (fast data velocity), Value (high data value). Among them, Volume is refers to the amount of data is big, data sets have more large scale has from the previous MB to GB or $\mathrm{TB}$, and now reach $\mathrm{Pb}$ level. Variety is refers to the large data types diversity, the date we deal with before are relatively simple, type is also very little, which are generally two-dimensional table structure of row data. Now, a large number of complex non-traditional information sources data has been produced by varieties of emerging channels and technology. Companies need to integrate and analyze data from a complex of traditional and nontraditional information sources; Velocity is refers to speed of data acquisition, processing and analysis fast growth and operation flow of large amount, due to the real-time data and combining the data to business processes and decision making processes of secondary reason, outgoing treatment changes from batch processing to stream processing, we can see how powerful processing capability of large data; and Value is refers to the growing amount of data, and data value is getting smaller and smaller, but the overall value of the data is more and more high. According to IDC (International Data Corporation) monitoring statistics, the global amount of data has reached 1.8ZB in 2011 (1ZB equal to 1 trillion GB, 1.8ZB is quite to the storage of 18 billion 1TB HDD), and this figure is still in the growth rate of two years to double the rate of growth, and it is expected that Global will have a total of 35zb amount of data to 2020, which increases nearly 20 times. Although the predicted industrial scale is different, the high growth rate shows that the development prospects of big data agencies are full of confidence. Therefore, the development and application of big data technology will become the focus of a new round of development of high technology, its application in the education industry will rise slowly.

\section{The problems faced by traditional preparatory basic computer teaching}

With the rapid development of computer technology, it has gradually become one of the fastest development, the most widely used science and technology, the industry also upgrade followed the progress of the times. Now computer technology began to develop into giant, miniature, intelligent and networking, and has the characteristics of multi polarization, multimedia, and it has superior performance and wide range of applications, which has become a indispensable tool in people's lives. Due to the increasing importance of computer technology, more and more applications, the technology has become a skill that college students must have. Because of the old of teaching equipment and the lack of teachers, the teaching of basic computer course can not keep up with the speed of the development of computer. Due to a number of ethnic minority students come from poor and backward area, backward local schools and educational resource inputs less severely limits 
the development of computer education in minority nationality areas, some minority students have less opportunity to contact computer, even some of them haven't see a computer. So it brings the following difficulties in the course teaching:

(1) The most profound impression that the basic computer course have been given is that the difficulty in teaching is quite big, the student is difficult to learn. In the traditional teaching mode, the theory knowledge in curriculum is not practical; the teaching content can not keep up with the development of computer technology in time, so there are some impeditive functions to improve the ability of students and promote the development of personality. In the teaching process of the course, the teachers give priority to the teaching, students often need to accept the passive learning, the idea of combining theory with practice can not be achieved. Therefore, it is easy to hit the enthusiasm of the students, and reduce their interest in learning, so that students are lack of innovation awareness, which will limit the students' ability of imagine and innovation.

(2) The large gap between the students. Due to the influence of family, environment and education, there is a great difference between the computer level and ability of the students.

(3) The students' learning initiative is poor. Students are full of curiosity about the surrounding while just entering the University, and also they did not attach importance to learning, and the learning model does not change in high school, so learning initiative is poor.

(4) The practical ability of students is not enough. It is difficult to analyze and solve the related professional knowledge. Basic computer needs the combination of the theory teaching and practice, however, the information literacy of vast majority of new is poor, and they are lack of practical ability to solve computer problems.

(5) The team cooperation consciousness of students is poor. Traditional basic computer mode tend to only focus on the cultivation of students' personal ability, ignoring the ability of the students' teamwork, communication and organization.

(6) The teaching content set up by school is relatively simple, teachers can not teach students according to the different majors; and teachers' teaching is difficult to form classic examples, teachers lack of interactivity, which easily lead to students be lack of learning motivation, so students are unable to produce a strong interest on the course.

\section{The opportunity that big data technology brings to basic computer}

Facing the above analysis in traditional basic computer teaching related problems, we can be see that: It is particularly important to establish student-centered concept, and cultivate students' autonomous learning interest, and set up teaching goal for students, and establish teaching mode having strong application, and improve the ability of independent innovation of students. And it is not enough to do this things only by teachers and students, so it is very important to make use of high and new technology of the third party. It is very effective to use big data technology to solve this problem proved by facts. The concept of big data technology has given in the beginning of the article, the development of big data technology plays a certain role in promoting the development of the network course learning courseware, teaching resources, teaching interaction and other aspects. The benefits of integrating curriculum courseware, teaching materials and other network resources to form a massive library through big data technology for the teaching of basic computer can be embodied in the following points:

(1) Improve the ability of personalized learning and promote adaptive teaching according to the characteristics of the students

Compared with the traditional education mode, big data has the advantages of large amount of information and strong pertinence. In the use of big data technology to learn computer basic course, there will be a lot of learning individuals, they can choose their own learning background and 
learning ability learning mode. In the process of teaching, the principle of taking students as the leading and taking practical application as the purpose should be taken to achieve the actual use of the ability of the students. The teach content should be reasonably set up in accordance with the principle of "learning less but fine". The targeted teaching measures should be taken according to the background knowledge of students in order to improve the students' learning interest. According to the technology of big data we should summarize the curriculum learning mode and learning rules, and set up the group learning prediction model, and actively explore effective teaching reform and solutions, and actively promote and the personalized learning mode.

(2) Improve the interactive and real-time of teaching

Big data is often the content of the classic teaching video, it is needed to test their knowledge of the situation after students completing the classroom learning. In the teaching mode of large data, interactive module should be set around teaching video, obviously, the interaction is particularly important to courage the students to ask questions. Therefore, in the classroom, it can greatly improve the teaching interactive and real-time if we turn the one-way indoctrination of the traditional teaching mode to exchange way of teachers and students to ask each other questions, and introduce the discussing and heuristic teaching method into teaching of computer course, and launch some excellent students to analyze questions from other students, and enable them to play the role of a teaching assistant, which can greatly improve the interactive and real-time of course teaching. The advantage is that the teacher's classroom atmosphere is good, the teaching enthusiasm is high, the student analysis and solving problem ability and interest is improved significantly, which can form a certain virtuous circle. The key advantage is that, students can deepen understanding of the discipline knowledge and the effective application by analyzing and solving problems, which can learn and apply elastically.

(3) Improve the quality of teaching

Big data technology can be applied in basic computer teaching platform, network curriculum resources of the platform are from the teacher teaching video, resources are uploaded through repeated tests, so this teaching mode that completely different with the traditional teaching method can improve the quality of teaching, which is known as "flipped classroom". Through this technology, we can change the traditional classroom teaching and practice after class to the face to face teaching and student Online Autonomous learning after class. Students can watch the teacher courseware resources after class, which can guide students to prepare in advance, and improve the learning desire of students, in class teachers discuss and learn focus on the content, effect test and effective communication and interaction with the students to strengthen the learning achievement, which can greatly improve teaching quality for basic computer.

(4) Facilitate teaching assessment

The generation of big data technology provides a new method for the teaching quality analysis and evaluation of the basic computer. The teaching platform can record the learning data of the whole country in real time, so big data teaching is of great help to the teaching quality inspection and analysis evaluation. In big data teaching platform, teachers can create unique learning files for each student, and record related state information of the knowledge and curriculum learning, and also optimize students' learning behavior model according to the real-time data, which can achieve real-time and interactive teaching. Teachers can also understand students' learning of curriculum knowledge and its trajectory, actual effect, interest bias and useful learning skills according to the students' learning behavior. Through the teaching evaluation can improve teaching methods, revise the teaching outline, reasonable arrange teaching contents, and improve teaching quality.

(5) Improve students practical application ability, better adapt to social needs 
In traditional basic computer teaching, the teacher is very difficult to know whether the students fully grasp if only arrange a few operation problems in practice teaching tasks. So it is difficult to promote teaching practice, which will directly affect the students' practical ability. students even have failed to grasp simple office automation operation after completion of the course, let alone writing programs. Therefore, the evaluation of teaching quality can not only rely on a single standard, but also should create the thinking environment more for students, and improve the ability of innovative thinking of students. For example, while having practice teaching in large data teaching platform, the teacher should let the student to learn independent, more guidance, reduce the direct intervention, and let the teachers to understand students' practical ability to manually, and launch in counseling, enhances the ability of analysis and solving problem of the student, then the students can better adapt to learning atmosphere.

(6) Expand the international education, while improving the level of teachers and students

With the rapid speed of economic development, economic globalization will become more and more obvious, which will inevitably bring about the internationalization of education. Economic development takes science and technology as the support point, and the development of science and technology can not be separated from the development of education. For example, the United States attaches great importance to the international exchange of students learning ability, not only find students in the world, but also send outstanding students to study abroad. The emergence of big data education platform provides a new way for the internationalization of higher education. On the basic computer, it is conducive to the development of basic computer course reform direction that letting teachers and students understand the current situation and development direction of teaching and learning. At the same time, on the big data platform, teachers and students can directly watch foreign teachers teaching video, understand the foreign teaching situation, and then guide the course teaching and learning, and further improve the overall level of teachers and students.

\section{Conclusion}

There are more and more problems caused by the education of traditional basis computer, which led to more and more serious crisis of basic computer teaching. In order to innovate basic computer teaching mode and teaching content, it provides a new model based big data technology for matriculation students basic computer teaching in this paper. Facing the more diverse groups of students, the adaptive teaching has been put forward according to their own characteristics of the students, which can improve students' individual learning ability, and emphasize the interaction learning between teachers and students. Big data was carried out to evaluate the teaching, which can achieve the goal on the teaching reform of college basic computer, and enhance the level of practice teaching, and expand the education internationalization, while raising the level of teachers and students, and enabling students to pass the matriculation learning and better adapt to learning atmosphere.

\section{Reference}

[1] J Zhigulen. Research status of weariness from Perspective of cultural philosophy of the National Matriculation students [D]. Inner Mongolia Normal University, 2011

[2] Ernie Val Sen. Mainland Xinjiang minority college students' learning adaptability of [D]. Dalian University of Technology, 2014

[3] Teng Xing, Ma Xiaoyi. China minority nationalities in higher education and education equality of national preferential policies [J]. Ethnic Studies, 2005,05:10-18107. 
[4] Chen Chao, Zhang Shunshi, Shang Shouwei, Sun Fei. Research on the application of power industry data in the large data background[J]. Modern Electronic Technology, 2013,24:8-11,14.

[5] Han Xinzhou. An analysis of calculation based on the thinking of vocational computer basic teaching with layers [J]. Journal of Yantai Vocational Construction, 2013,02:44-46.

[6] Zhong Qi, Wu Zhiyong. Research on the "micro course" teaching mode of basic computer courses in Colleges and universities [J]. Modern educational technology, 2014,02:26-33.

[7] Song Tian, Li Fengxia, Cai Qiang, Li Zhongjun, Shi Min trees. For Computational Thinking of university computer foundation curriculum teaching content reform [J]. Computer education, 2014,03:7-11.

[8] Sun Shuxia. Exploration and Practice on the reform of computer basic course in local colleges and universities [J]. China University teaching, 2014,04:59-62.

[9] Dai Zhenhua MOOC and the application of large data technology in the basic teaching of college computer [J]. Computer and telecommunications, 2014,06:41-43.

[10] Wan Li. Enlightenment of MOOC to the teaching reform of computer basic course in Colleges and Universities -- Taking Hunan University of Science and Engineering as an example [J]. Journal of Hunan Institute of Science and Technology (Natural Science Edition), 2014,04:83-85,88.

[11] Xu Ying, Sun Qi. Big data era computer application foundation curriculum teaching innovation study [J]. Information and computer (Theory Edition), 2015,13:172-173175.

[12] Yin Yanli, Zhu Huanle, Wu Meijie. Preliminary computer basic teaching in the course of the development of micro lesson [J]. Intelligence, 2015,23:50.

[13] Liu Ya. Application of PBL+LBL dual track model in college computer basic teaching [J]. College Education, 2015,08:120-121124.

[14] Cui Suli, Sun Man. Research on the foundation of computer based on CDIO concept [J]. Public science and technology, 2012,03:213-214143.

[15] Gong Pei Zeng, Yang Zhiqiang. University of Computational Thinking in the teaching of basic computer culture [J]. Chinese university teaching, 2012,05:51-54.

[16] Yang Guanglin. The application of the teaching model of problem based learning in the basic teaching of Computer Science in the University of Jiamusi [J]. Journal of College of education, 2012,05:196.

[17] Li Zhiming. Study on the teaching mode of computer basic course in university based on digital network resources [D]. Northwest Normal University, 2014

[18] Zhu Yanli, Guo Xiaojuan. Application of data mining technology in the reform of computer basic teaching mode [J]. computer development and application, 2010,06:18-19,22.

[19] Zhang Yanyan. Application Research of micro project learning in the teaching of "computer application foundation" [D]. Shaanxi Normal University, 2013 